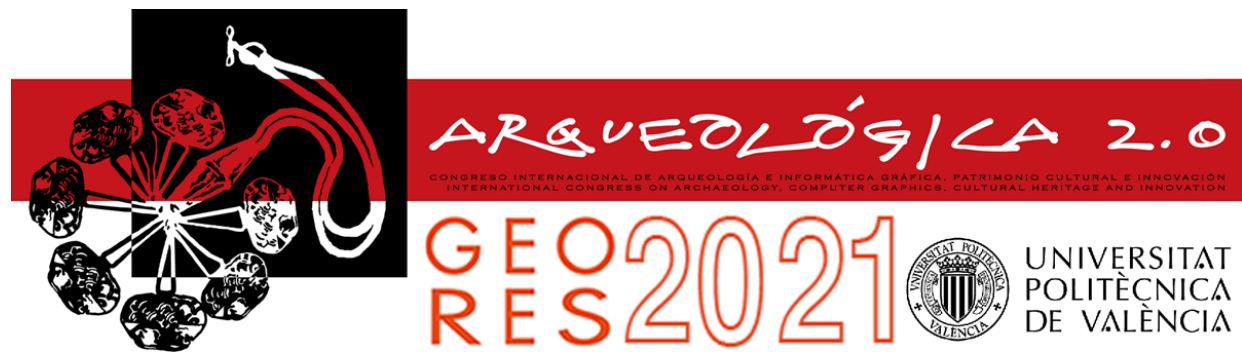

Proceedings of the joint international event $9^{\text {th }}$ ARQUEOLÓGICA

$2.0 \& 3^{\text {rd }}$ GEORES

Valencia (Spain).

26-28 April 2021

Received: 27/11/2020

Accepted: $13 / 03 / 2021$

DOI: https://doi.org/10.4995/Arqueologica9.2021.12132

\title{
3D GIS FOR A SMART MANAGEMENT SYSTEM APPLIED TO HISTORICAL VILLAGES DAMAGED BY EARTHQUAKE
}

\author{
Alban Gorreja*, Francesco Di Stefano, Fabio Piccinini, Roberto Pierdicca, Eva Savina Malinverni \\ Dipartimento di Ingegneria Civile, Edile e Architettura (DICEA), Università Politecnica delle Marche, Via Brecce Bianche 12, 60131 \\ Ancona, Italy. a.gorreja@pm.univpm.it; f.distefano@pm.univpm.it; f.piccinini@pm.univpm.it, r.pierdicca@staff.univpm.it; \\ e.s.malinverni@staff.univpm.it
}

\begin{abstract}
:
Historic villages are included in the category of cultural heritage to be safeguarded and preserved. Accidental events, such as earthquakes, represent a threat to their vulnerability. Usually, the analyses of damaged buildings, which are part of these villages, are then carried out singularly, not fostering instead the constitution of mapping at the urban scale that allows a more complete knowledge of the state of damage and risk of adjacent buildings and of the entire area. An information system such as 3D GIS is a suitable solution for this purpose. The aim of this research is to develop a SMART management system for preservation activities of historical villages through the management of heterogeneous types of data, from the survey to the technical documentation. The workflow is structured as follows: (i) Data acquisition: the survey of a small village was carried out by combining geomatic techniques necessary to produce a complete point cloud; (ii) 3D modelling: data extrapolation from the post-processed point cloud and subsequent generation of a GIS-based on 3D model thanks to the creation of DTM and DSM of the area of interest; (iii) Knowledge modelling: a geospatial information model is necessary to put in order and together all the information collected for the whole village and each building composing it; (iv) SMART management modelling: improvement of the information management system that guarantees the possibility to enrich and update data at any time. This research paves the way to develop a web platform where GIS data would be imported for a digital twin approach.
\end{abstract}

Keywords: historical village, GIS, knowledge modelling, SMART information management system, earthquake

\section{Introduction}

In recent years the use of three-dimensional (3D) modelling software and open-source platforms for SMART data management of urban and building projects has become increasingly frequent. The constantly updated regulations suggest and, in some cases, enforce the adoption of new sustainable, advanced and more accessible digital information systems. (Nam \& Pardo, 2011; Vinodkumar, 2016). This SMART approach is not only intended to represent optimal management of the data of one or more projects after a seismic event, but it also serves to define preventive measures (real-time data visualisation, disasters prediction, etc) that can be taken to deal with this type of emergency.

As a case study for this research project, one of the many villages damaged by the seismic events that hit central Italy in 2016 is chosen. Villages that represent a fullfledged historical and cultural heritage. Among these, there is a small village called "Gabbiano", located in the municipality of Pieve Torina, in the Marche region in Italy. It is characterized by a historic centre with a limited number of buildings that have suffered damage as a result of the earthquake that has affected this area. The aim of this research activity is to create a robust information system for the management of various types of data, from the survey to the technical documentation up to the following phases of the project through an information system such as GIS. The first step is to create a 3D model obtained through a combination of geomatic techniques. The entities composing the 3D geometric model become the object features of an organized knowledge modelling in order to have a precise connection with geometries, defined by a semantic representation following the CityGML schema. This leads to a SMART approach to the information management system that collects not only spatial data but also topological and not-geometrical data. The enriched knowledge modelling linked to the 3D object may represent a starting point for the digital twin approach, useful to manage the monitoring and restoration activities (Ketzler et al., 2020). This solution can be replicated in other similar case studies to safeguard these small villages that risk losing their historical, architectural, urban and social identity as a result of these accidental events. 


\section{State of the art}

The GIS platform is well suited for data management at the urban scale in a given geographical area. Moreover, 3D GIS software gives a three-dimensional model of the topographic representation of the terrain with the geolocalization of the buildings in the form of volumes at the various LODs (Level of Details) (Almeida, Gonçalves, Falcão, \& Ildefonso, 2016). It incorporates 3D territorial and buildings information giving a stronger, richer and clearer visual impact compared with a simple twodimensional GIS mapping. A 3D GIS can be used as a reference 3D map for any urban planning management activities and among them also in case of seismic emergency (Lenticchia \& Coïsson, 2017). In particular, GIS is suggested as a suitable tool for the risk mapping or better the spatial extent of risk in which document the effects of hazard situations, according to the ISO/IEC 31010:2009 and the Recommendations for National Risk Assessment (Poljanšek et al., 2019). An example of risk assessment in GIS was implemented for the data management of expected seismic scenario analysing a building complex in Lisbona (llic, Bento, \& Cattari, 2020). Other case studies to assess and manage the seismic damages and vulnerability in GIS were adopted for Scarperia (Cardinali et al., 2020) or to monitor the recovery plan after earthquake in L'Aquila (Contreras Blaschke, Tiede, \& Jilge, 2016).

It's possible to convert the 3D GIS modelling in an open data system thanks to the CityGML standard (OGC, 2020). CityGML is a common semantic information model for the representation of $3 \mathrm{D}$ urban objects that can be shared over different applications. It is an open-source data model and eXtendible Markup Language (XML)based format for the creation of city models (Gröger, Kolbe, Nagel, \& Häfele, 2012). CityGML is widely used in GIS city modelling and represents an open recognized standard and well-defined ontology. The hierarchical structure of data is provided by CityGML that thanks to its schema allows having a semantic representation that defines relationships between the various entities composing the 3D city model (Malinverni et al., 2020). CityGML-based approach that leads to defining a knowledge modelling where not only spatial but also external information, like topological, architectonical, technical data, is managed (Agugiaro, 2016). The benefits of using a centralized GIS-based information system, developed in CityGML environment, may guarantee an efficient, well-structured and SMART city management system (Banerjee, Chakraborty \& Das, 2020). This open-source GIS tool allows to map the damages and support the emergency planning for risk and hazard scenario like an earthquake (Pollino et al., 2012; Francini, Artese, Gaudio, Palermo, \& Viapiana, 2018).

\section{Methodology}

Following the data processing of the data acquired through the geomatic survey, which allowed the creation of mesh of the terrain, the volumes of the buildings in a 3D GIS environment can be generated. In parallel to the geometric modelling is defined a CityGML schema identifying the entities, such as roads, buildings and their features, composing the 3D model of the village and their relationships. This knowledge model will represent the starting point for a SMART management modelling of the entire village promoting advanced data management ensuring access by different figures as project experts and private clients who can constantly update with new data at any time.

The workflow shown in Figure 1 will be described below.

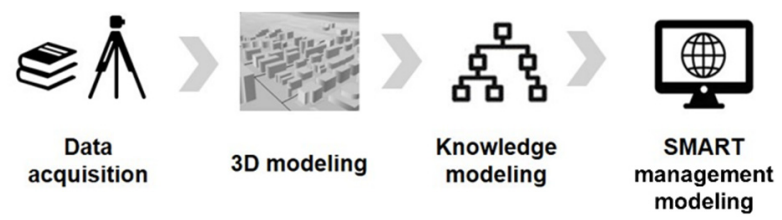

Figure 1: The research workflow.

\subsection{Data acquisition}

The survey of the small village "Gabbiano" was carried out by integrating three geomatic techniques: GNSS (Global Navigation Satellite System), terrestrial LIDAR (Light Detection And Ranging) and aerial photogrammetry from UAV (Unmanned Aerial Vehicle). The aim was to obtain the most comprehensive point cloud possible from which to create a complete $3 \mathrm{D}$ model. In fact, the terrestrial LIDAR is very useful to detect building facades facing the narrow alleys of the village, the aerial photogrammetry to complete the survey in detecting roofs and the GNSS to collect the coordinates of specific points through which georeferencing the whole generated point cloud. The terrestrial LIDAR scans registration process has led to a point cloud with a total network RMSE (Root Mean Square Error) of $6.82 \mathrm{~cm}$, while using $10 \mathrm{GCP}$ (Ground Control Points) for the photogrammetric processing of aerial images, a reconstruction with RMSE of $4.82 \mathrm{~cm}$ was achieved. These two have been merged into one unified point cloud (Fig. 2).

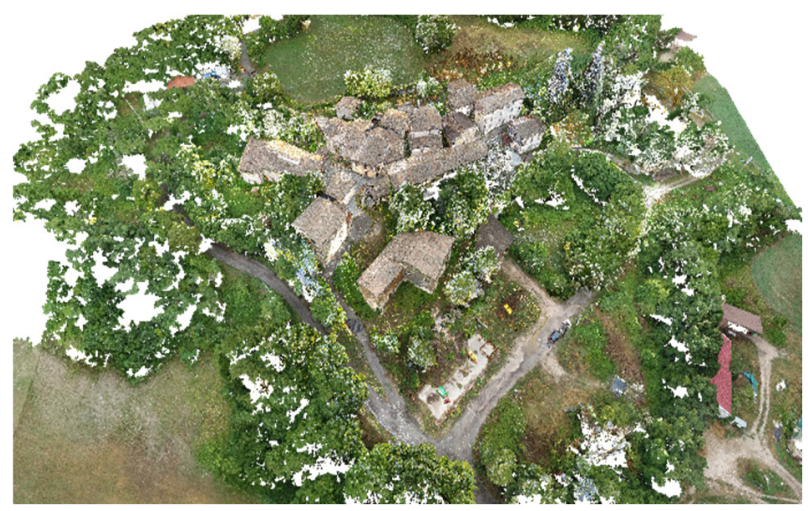

Figure 2: Unified point cloud.

\subsection{D modelling}

The availability of a numerical mapping at $1: 10.000$ scale by the Marche region, where the equidistance between contour lines is 10 meters, couldn't give a detailed 3D model of the small village. Therefore, the absence of an open-data platform that provides GIS data has led us to obtain the 3D model through the generation of mesh from the processed point cloud.

The extrapolation of data from point is useful for 3D modelling and can be conducted through an open-source 3D model management software. In this context CloudCompare (2021) was chosen, in order to ensure that the required data, such as the buildings base plan and their height above ground, are precisely calculated, 
taking into account the non-constant morphological distribution of the terrain. The "Rasterize" command allows to generate DTM (Digital Terrain Model) and DSM (Digital Surface Model) raster images. The latter is obtained using the entire point cloud and considering the maximum height of the points in each cell of the grid. For the former instead only the ground points must be used, which can be extracted thanks to the Cloth Simulation Filter (CSF) (Zhang et al., 2016), considering the average height of the points for each cell. In the empty cells, the height is interpolated. Importing the DTM in raster format in GIS it is easy to reproduce the TIN (Triangulated Irregular Network) model of the terrain on which the volumes of buildings are placed.

In order to obtain a correct map of the buildings, it has been drawn in CAD software using the point cloud as reference. Then we imported it as a vector layer of polygons in GIS to enrich the data in its attribute table. The mean height values from DTM and DSM on the area of each building is extracted thanks to the "Zonal Statistic" function, while the difference between them can be easily obtained using the field calculator. The latter constitute the extrusion height to use on each polygon to build up the 3D entities with good volumetric representation. In this case LOD 1 (Level of Detail - OGC, 2020) has been reached (Fig. 3). This level will increase once other useful information will be added to enrich the 3D modelling.

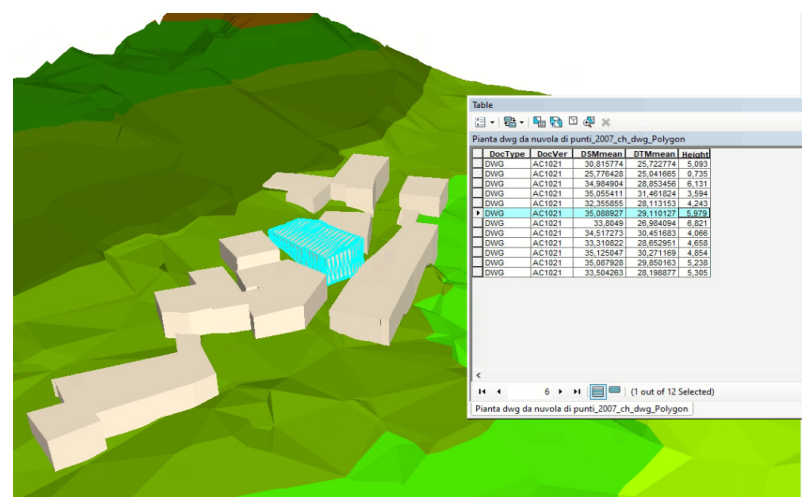

Figure 3: 3D GIS model (LOD 1).

\subsection{Knowledge modelling}

The 2016 seismic events made the analysis of the current state of the small village a priority for an adequate and rapid preservation project that would also takes into account the safety works carried out in the aftermath of the earthquake. For this study, the possibility to collect all these data into an information system enriching a 3D model represents a fundamental knowledge step for planning forthcoming interventions. An example of a detailed description of the damage state of these buildings in Italy is outlined on the technical data sheets called AeDES, whose acronym stands for "building operability and damage in post-earthquake emergency" (Baggio et al., 2007), recorded by the Italian Civil Protection. Through GIS it will be possible to create a link to these documents for each building and try to describe the state of damage by enriching the 3D model with thematic mappings of the decay (Malinverni, Giuliano, \& Mariano, 2018; Tsilimantou, Delegou, Nikitakos, Ioannidis, \& Moropoulou, 2020). Once collected the AeDES data sheets, the operation adopted is to store such files in a webserver and link each file with its building in the model. Using any GIS software, it can be done manually by adding to the table of attributes of the project a new column containing the reference path to where the information is stored. For large and complex models, it's not handy doing this for every building manually, an automatic process is suggested.

Since the 3D GIS model was converted into a CityGML model, many modifications, such as further data enrichment or even changes to the elements as well as the topography, can be done. In this step, corresponding between GIS and CityGML is possible to automatize the process of enriching information, such as AeDES sheets. A geospatial information model has been created with the aim to reach a common $3 \mathrm{D}$ city model allowing the reuse of data in other application fields of city management. These features make CityGML the best choice to follow. A new 3D model means a new ontological schema, necessary to put in order and together all the information collected for the entire village. In short, each building is represented by a CityObject of the village. Information related to each building are linked to the _CityObject with other features (subclass) thanks to the CityGML schema. The externalReference, already provided by CityGML, allows to link other types of data to the project object, for example technical documents (Fig. 4).

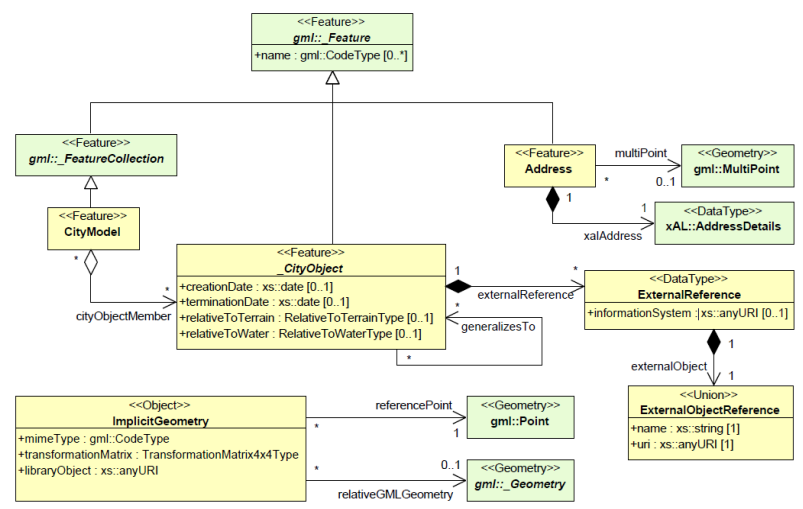

Figure 4: CityGML schema (OGC).

As just outlined, it is necessary to create a relationship between the 3D city object and external documents, but externalReference allows to link these data to the whole 3D city model, not for each single object composing the city model. A solution that can be adopted consists of using another element of the CityGML schema. The Address can be filled with different data for each building. Through FME (Feature Manipulation Engine) software it is possible to create a workflow of transformation tools that can modify the structure of the model itself. FME is a data integration and transformation platform. Leaving an empty column of an attribute within the GIS model, it is possible to fill it with information through FME (2019). It can be done automatically if the data are previously stored in XML format. FME allows redirecting the information stored in the XML to each building using the Address (Fig.5).

This means that the software will get a hypothetic address, write it in the empty attribute previously created. At this point, the attributes of each building in the CityGML model will show a link to the webserver (or local host, depending on where the data is stored) (Fig. 6). This ontological approach represents a valuable solution to link information to the 3D GIS model. 


\subsection{SMART management modelling}

A parametric navigable "virtual" model is very different from the previous systems where the information was limited to something graphic. Today, the advent of new technologies makes it possible to create information systems where information can not only be visualised in real-time in a navigable $3 \mathrm{D}$ environment, but can also be entered in real-time, processed and read by a user. In addition, given the complexity of the territory and cities, the information related to them may come from different sources and refer to different fields of application. A system designed in this way is a structure that represents the dual reality for which it is called a 'digital twin'. One of the aims of this research is to address this challenge by providing features and data from a GIS information system that will form part of, or better still define the basis for a digital twin model. Therefore, a working process as explained in the previous paragraph can help to move towards a detailed representation of reality. Generating a workflow where information is updated in a very short time can be a further development of the information management of an urban area. It may also save time and resources, both in the research project and for figures working in the AEC (Architecture, Engineering and
Construction) field and public institutions. The involvement of several figures within the planning of a recovery project such as the reconstruction of a village hit by an earthquake also allows common and optimal choices and decisions to be taken in a short time thanks to this open data platform (Artese \& Achilli, 2019).

These innovative aspects that allow an improvement of data management through an information system like GIS give it a development of the knowledge modelling towards SMART management modelling.
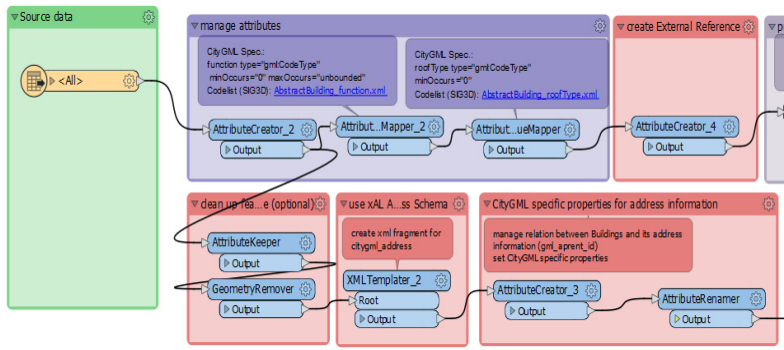

Figure 5: FME workflow showing address and external reference data enrichment.

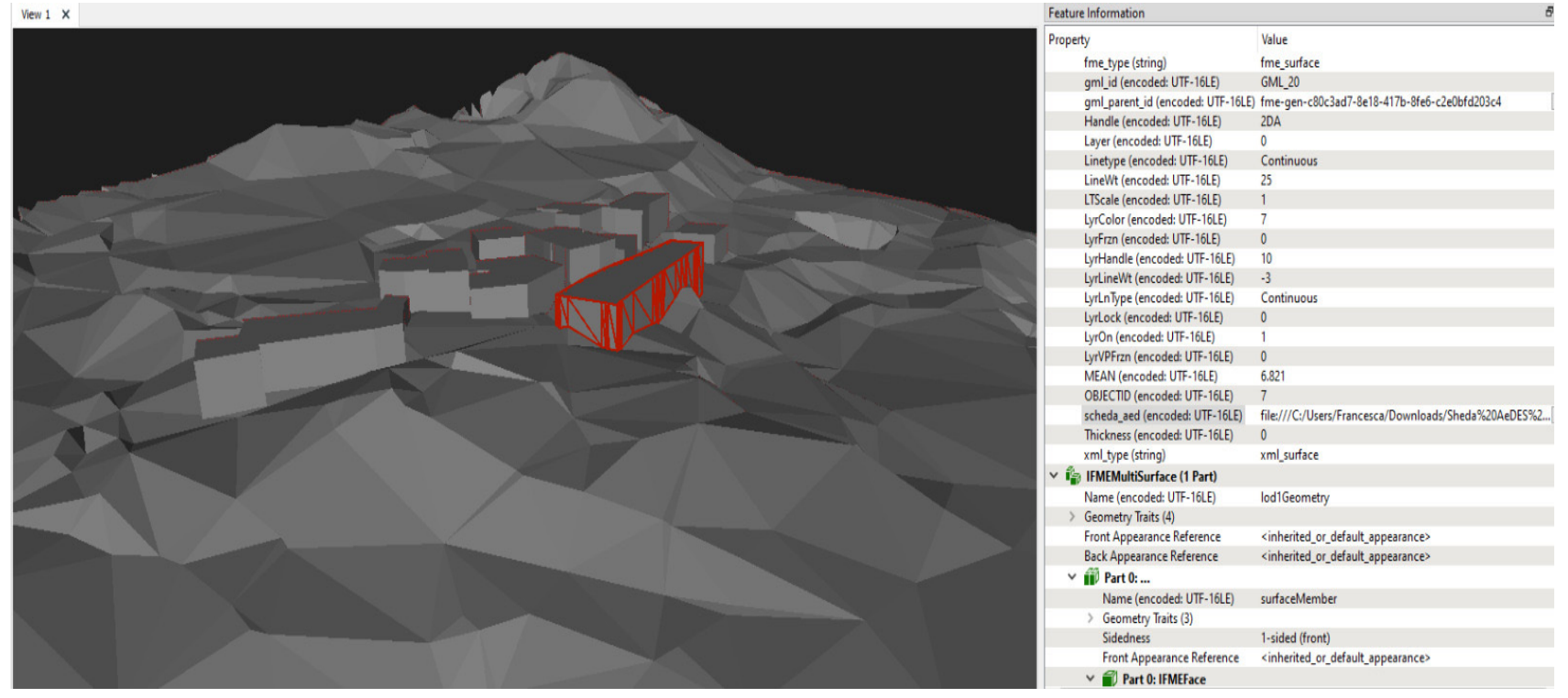

Figure 6: 3D CityGML: model and related attributes to the selected building.

\section{Conclusions and future works}

This is an ongoing project, there are only preliminary results of this research activity such as the creation of the 3D GIS model following the processing of the survey data and the definition of CityGML knowledge modelling for information management. The next step will be to perform this knowledge modelling adopting a SMART approach to the management system in order to ensure sustainability, accessibility, including the time factor needed to define the lifecycle of the interventions to be carried out. Phase also characterized by the constant data enrichment or updating of the information at any time.

In case of small villages, a large scale is required, which means that the information, associated with it, are significant. While a BIM model offers a great opportunity to represent a high level of detail on an architectural scale, it cannot guarantee this for an entire village. A 3D GIS model will be more appropriate, where the information contained is not only a 3D representation at a low LOD but contains all the information linked to the related model but also makes relationships between the different entities composing the village, from the terrain to the buildings themselves. But it's not excluded that, after a process of data standardization using CityGML or graph databases and data conversion into an exchange format (Malinverni et al, 2020), it will ensure a possible integration of GIS data with any BIM data of each building (Ma \& Ren, 2017), guaranteeing a sort of interoperability within a CDE (Common Data Environment) that will facilitate the archiving, sharing and dissemination of information. 


\section{Acknowledgements}

This work is part of the project "RICOSTRUZIONE SMART DEI BORGHI STORICI", which has been financed by the "PROGRAMMA OPERATIVO REGIONALE DEL FONDO EUROPEO DI SVILUPPO REGIONALE POR MARCHE FESR 2014/2020".

\section{References}

Agugiaro, G. (2016). First steps towards an integrated CityGML-based 3d model of Vienna. ISPRS Annals of Photogrammetry, Remote Sensing \& Spatial Information Sciences, 3(4). https://doi.org/10.5194/isprsannals-III-4139-2016

Almeida, A., Gonçalves, L., Falcão, A., \& Ildefonso, S. (2016). 3D-GIS Heritage City Model: Case study of the Historical City of Leiria. Proceedings of the 19th AGILE International Conference on Geographic Information Science, Helsinki, June 14-17.

Artese, S., \& Achilli, V. (2019). A GIS tool for the management of seismic emergencies in historical centers: how to choose the optimal routes for civil protection interventions. Int. Arch. Photogramm. Remote Sens. Spatial Inf. Sci., XLII2/W11, 99-106. https://doi.org/10.5194/isprs-archives-XLII-2-W11-99-2019

Baggio, C., Bernardini, A., Colozza, R., Corazza, L., Della Bella, M., Di Pasquale, G., Dolce, M., Goretti, A., Martinelli, A., Orsini, G., Papa, F., \& Zuccaro, G. (2007). Field Manual for post-earthquake damage and safety assessment and short-term countermeasures (AeDES). JRC Scientific and Thechnical Reports.

Banerjee, S., Chakraborty, C., \& Das, D. (2020). An Approach towards GIS Application in Smart City Urban Planning. Internet of Things and Secure Smart Environments: Successes and Pitfalls, 71.

Cardinali, V., Cristofaro, M. T., Ferrini, M., Nudo, R., Paoletti, B., \& Tanganelli, M. (2020). An Interdisciplinary Approach for the Seismic Vulnerability Assessment of Historical Centres in Masonry Building Aggregates: Application to the City of Scarperia, Italy. The International Archives of Photogrammetry, Remote Sensing and Spatial Information Sciences, 44, 667-674. https://doi.org/10.5194/isprs-archives-XLIV-M-1-2020-667-2020

CloudCompare. (2021). CloudCompare - Latest stable release (2.11.3 Anoia). Retrieved November 12, 2020, from https://www.danielgm.net/cc/

Contreras, D., Blaschke, T., Tiede, D., \& Jilge, M. (2016). Monitoring recovery after earthquakes through the integration of remote sensing, GIS, and ground observations: the case of L'Aquila (Italy). Cartography and Geographic Information Science, 43(2), 115-133. https://doi.org/10.1080/15230406.2015.1029520

FME. (2019). FME Workbench 2019.2. Retrieved November 12, 2020, from https://www.safe.com/

Francini, M., Artese, S., Gaudio, S., Palermo, A., \& Viapiana, M. F. (2018). To support urban emergency planning: A GIS instrument for the choice of optimal routes based on seismic hazards. International Journal of Disaster Risk Reduction, 31, 121-134. https://doi.org/10.1016/j.ijdrr.2018.04.020

Gröger, G., Kolbe, T. H., Nagel, C., \& Häfele, K. H. (2012). Open Geospatial Consortium OGC City Geography Markup Language (CityGML) Encoding standard.

Ilic, J. M., Bento, R., \& Cattari, S. (2020). 3DGIS representation for supporting seismic mitigation policies at urban scale: The case study of Lisbon. Journal of Cultural Heritage, 45, 265-278. https://doi.org/10.1016/j.culher.2020.04.001

ISO 31000:2009, Risk management - Principles and guidelines

IEC 31010:2009, Risk management - Risk assessment techniques

Ketzler, B., Naserentin, V., Latino, F., Zangelidis, C., Thuvander, L., \& Logg, A. (2020). Digital Twins for Cities: A State of the Art Review. Built Environment, 46(4), 547-573. https://doi.org/10.2148/benv.46.4.547

Lenticchia, E. \& Coïsson, E. (2017). The use of GIS for the application of the phenomenological approach to the seismic risk analysis: the case of the Italian fortified architecture. International Archives of the Photogrammetry. Remote Sens Spat Inf Sci, 42, 39-46. https://doi.org/10.5194/isprs-archives-XLII-5-W1-39-2017

Ma, Z., \& Ren, Y. (2017). Integrated application of BIM and GIS: an overview. Procedia Engineering, 196, $1072-1079$. https://doi.org/10.1016/j.proeng.2017.08.064

Malinverni, E. S., Giuliano, A. A., \& Mariano, F. (2018). 3D information management system for the conservation of an old deserted military site. In 2018 Metrology for Archaeology and Cultural Heritage (MetroArchaeo) (pp. 188-192). IEEE. https://doi.org/10.1109/MetroArchaeo43810.2018.13618

Malinverni, E. S., Naticchia, B., Lerma, J. L., Gorreja, A., Uriarte, J. L., \& Di Stefano, F. (2020). A semantic graph database for the interoperability of 3D GIS data. Applied Geomatics, 1-14. https://doi.org/10.1007/s12518-020-00334-3

Nam, T., \& Pardo, T. A. (2011). Smart city as urban innovation: Focusing on management, policy, and context. In 
Proceedings of the 5th international conference on theory and practice of electronic governance, 185-194. https://doi.org/10.1145/2072069.2072100

OGC. (2020). Open Geospatial Consortium - CityGML. Retrieved November 12, 2020, from https://www.ogc.org/standards/citygml

Poljanšek, K., Casajus Valles, A., Marin Ferrer, M., De Jager, A., Dottori, F., Galbusera, L., Garcia Puerta, B., Giannopoulos, G., Girgin, S., Hernandez Ceballos, M., Iurlaro, G., Karlos, V., Krausmann, E., Larcher, M., Lequarre, A., Theocharidou, M., Montero Prieto, M., Naumann, G., Necci, A., Salamon, P., Sangiorgi, M., Sousa, M. L, Trueba Alonso, C., Tsionis, G., Vogt, J., \& Wood, M. (2019). Recommendations for National Risk Assessment for Disaster Risk Management in EU, EUR 29557 EN, Publications Office of the European Union, Luxembourg, 2019, ISBN 97892-79-98366-5 (online). https://doi.org/10.2760/084707 (online), JRC114650.

Pollino, M., Della Rocca, A. B., Fattoruso, G., La Porta, L., Lo Curzio, S., Arolchi, A., James, V., \& Pascale, C. (2012). Open source GIS Tools to Map Earthquake Damage Scenarios and to Support Emergency. GEOProcessing 2012: The Fourth International Conference on Advanced Geographic Information Systems, Applications, and Services.

Tsilimantou, E., Delegou, E. T., Nikitakos, I. A., loannidis, C., \& Moropoulou, A. (2020). GIS and BIM as Integrated Digital Environments for Modeling and Monitoring of Historic Buildings. Applied Sciences, 10(3), 1078. https://doi.org/10.3390/app10031078

Vinodkumar, T. M. (2016). Geographic information system for smart cities. Copal Publishing Group

Zhang, W., Qi, J., Wan, P., Wang, H., Xie, D., Wang, X., \& Yan, G. (2016). An easy-to-use airborne LiDAR data filtering method based on cloth simulation. Remote Sensing, 8(6), 501. https://doi.org/10.3390/rs8060501 